Sociohistórica, $n^{\circ}$ 41, e055, 1er. Semestre de 2018. ISSN 1852-1606

Universidad Nacional de La Plata. Facultad

de Humanidades y Ciencias de la Educación.

Centro de Investigaciones Socio Históricas

\title{
Capitalismo y producción de subjetividad.
}

\author{
Reseña de Alemán, Jorge. Horizontes neoliberales en la \\ subjetividad,Grama ediciones, Buenos Aires. 2016. 192 p.
}

\section{Paula Zubillaga *}

* Instituto del Desarrollo Humano- Universidad Nacional de General Sarmiento - CONICET, Argentina

paulazubillaga@gmail.com

Cita recomendada: Zubillaga, P. (2018). Capitalismo y producción de subjetividad. Sociohistorica, 41, e055. https://doi.org/10.24215/18521606e055 


\section{Capitalismo y producción de subjetividad.}

Reseña de Alemán, Jorge. Horizontes neoliberales en la subjetividad,Grama ediciones,

Buenos Aires. 2016. 192 p.

Paula Zubillaga

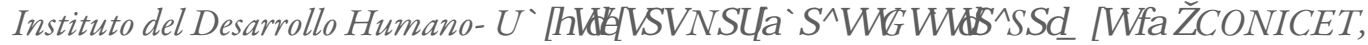

Argentina

paulazubillaga@gmail.com

Horizontes neoliberales en la subjetividad es el producto de una lectura psicoanalítica del capitalismo y sus efectos. Se trata de un conjunto de textos del escritor y psicoanalista argentino Jorge Alemán en los que desarrolla su tesis sobre el neoliberalismo como modo de producción de subjetividad. Reúne conversaciones, conferencias, entrevistas, intervenciones en jornadas y foros de psicoanálisis entre los años 2015 y 2016, en los cuales reflexiona en torno al neoliberalismo -como formación específica de la lógica del capital- y la posibilidad de una lógica emancipadora a partir de preguntarse: ¿Qué impide al neoliberalismo consumarse como "crimen perfecto"? ¿Qué hay en el sujeto que no sea colonizable por la estructura del capital? ¿Cómo el discurso analítico, que impera sobre la singularidad del sujeto, puede generar un hecho político que trascienda a esa singularidad?

Si bien los escritos que componen el libro están enmarcados en un aparato conceptual delimitado por el pensamiento de Sigmund Freud, Karl Marx, Martin Heidegger y Jacques Lacan, en los mismos el autor dialoga con diversos pensadores como Walter Benjamin, Emmanuel Kant, Louis Althusser, Antonio Gramsci, Georg Hegel, Alain Badiou, Slavoj Zizek, Gilles Deleuze, Toni Negri, Michel Foucault y, sobre todo, con Ernesto Laclau -a quien considera el inventor más radical del campo posmarxista- y su teoría del populismo. Esta diversidad de pensadores se debe a que el libro une psicoanálisis con filosofía y política.

Los distintos apartados de Horizontes neoliberales están relacionados entre sí y versan sobre los mismos conceptos y temas: qué es y cómo se construye hegemonía, el capitalismo como poder no hegemónico, la especificidad del neoliberalismo, aquello de lo que este no puede apropiarse, la posibilidad de la emancipación y la necesaria diferenciación entre sujeto y subjetividad, sin la cual no puede entenderse su tesis.

La idea central que recorre y estructura el libro es que el neoliberalismo es el primer régimen histórico que disputa el campo de sentido, la representación y la producción biopolítica de subjetividad. Es decir, su especificidad se basa en que ya no se trata de la clásica alienación -esa parte extrañada de uno mismo que se puede recuperar a través de una praxis-, sino que es algo más radical y grave, puesto que se trata de la producción e invención de la subjetividad misma: apunta a la producción de un "hombre nuevo" engendrado desde su propio presente, un sujeto sin legados simbólicos y sin interrogantes por lo singular que habita en cada uno. Esta producción instala al sujeto en un lugar que está siempre más allá de sus posibilidades y que lo confronta todo el tiempo con lo que no puede.

En este sentido, el autor postula que ha surgido un nuevo tipo de subjetividad que denomina "empresario de sí mismo", alguien que piensa, gestiona y organiza su vida, la relación consigo mismo y con los otros, como una empresa de rendimiento. Esto es, una subjetividad que concibe la vida bajo una performance de sexualidad, deporte y trabajo- donde priman las lógicas empresariales de rendimiento, optimización de recursos y competencia, que confrontan al sujeto con una exigencia frente a la cual no da la talla y siempre está endeudado. 
De esta forma, Alemán sostiene que esta lógica de rendimiento ilimitado, de sujetos arrojados a una situación que los desborda, que está más allá de sí mismo y de sus posibilidades, ha expandido la depresión, entendida como una patología de la responsabilidad, una patología del sujeto que se hace cargo de no haber cumplido, de no estar a la altura de sus exigencias. El autor sostiene así que se trata de una carrera ilimitada y circular de explotación a uno mismo en la culminación del rendimiento. En consecuencia, ya no se trata de la vieja dominación que nos oprime, sino que es una dominación invisible, interna y constitutiva.

Asimismo, la producción de una subjetividad neoliberal - "el emprendedor de sí", "el deudor", "la nuda vida", "el in-empleado estructural”-, sólo es explicable, según el autor, por la coerción del superyó, su engendramiento de culpa y la necesidad de castigo que el neoliberalismo coloniza con sus dispositivos. La producción de este tipo de subjetividad va de la mano de la extensión del pánico, el terror y la amenaza, a la vez que de las terapias de autoayuda, el managements y el coaching. De esta forma, el neoliberalismo logra que los propios sujetos se autodisciplinen porque están invadidos por el pánico, y porque sienten, a su vez, que todo está puesto en duda, que todo está en crisis.

Así, el neoliberalismo opera de forma tal que los sujetos, en una suerte de "servidumbre voluntaria", son capaces de atentar contra sus propios intereses, lo que implica sujetos capaces de votar o adherir a proyectos que los van a perjudicar, y sujetos capaces de hacerse daño a sí mismos con tal de destruir a otro. De esta manera, la maldad ya no es el egoísmo - puesto que el egoísta todavía se ocupa de sí mismo-, sino que consiste en ser capaz de incluso hacerse daño a uno mismo con tal de perjudicar al otro. A su vez, el neoliberalismo coloca al sujeto en una situación que le hace sentir que, cada vez que hay un problema social, es en realidad una dificultad personal. Es decir, el dispositivo transforma en culpa personal lo que es un hecho del sistema, hace sentir como un fracaso personal lo que ha sido producido catastróficamente a escala mundial. Por esta razón, la epidemia de depresión que ve extenderse, se debe a que se traduce subjetivamente algo que pertenece a un hecho pura y exclusivamente político.

Frente a esta lógica del capital, el autor sostiene que la única forma de enfrentarla es a través de la política. Sin embargo, plantea que ninguna transformación política es posible si no se pone en juego aquello que el circuito de la mercancía no puede capturar, esto es, lo inapropiable. Según el autor, el capitalismo opera produciendo dispositivos que destruyan el campo simbólico que precede al sujeto y que hace posible en cada uno una historia, una memoria y una temporalidad. Es decir, sostiene que el capitalismo rechaza la diferencia que constituye a cada sujeto, aquello que lo hace incomparable, irrepetible, irreductible y no evaluable. De esta forma, Alemán considera que la diferencia entre sujeto - que no puede ser construido-y subjetividad -que es construida y producida-, es una diferencia política clave, puesto que el "botín de guerra" del neoliberalismo es la producción de subjetividad. Así, para que el crimen no sea "perfecto”, el poder no debe capturar el núcleo ontológico del sujeto.

En esa línea, si el sujeto es un efecto del lenguaje y no puede ser producido, es allí donde se puede buscar qué sería inapropiable para el neoliberalismo. Es decir, aquello que impide que este se consume como "crimen perfecto". En este sentido, sostiene que la condición de posibilidad de una experiencia política transformadora es lo que denomina "Soledad: Común". Este concepto -que desarrolló en su libro del mismo nombre- es clave, y se puede traducir como la dimensión colectiva de aquello que la producción de subjetividad neoliberal no colmó, dejó vacío, es decir, lo inapropiable. De esta forma, no hay posibilidad de pensar un acontecimiento político sin las marcas de la "Soledad: Común”, en otras palabras, de un colectivo de singularidades.

El autor concluye que estamos frente a una dominación que se ha naturalizado, de modo tal que su mayor poder es presentarse como invisible y consustancial al sujeto. Sin embargo, mantiene un pensamiento positivo al sostener que, al ser una realidad histórica, no es eterno. De este modo, plantea que ninguna realidad, por más consistente y hegemónica que se presente, debe ser considerada como definitiva. No obstante, toma ciertos reparos y sostiene que deben pensarse proyectos emancipatorios que no sean sostenidos en lógicas sacrificiales, es decir, proyectos que no impliquen miles de muertos para concretarse. 
De esta forma, para Alemán, el hecho político contemporáneo pasa por definir qué es el sujeto, porque ya no se puede hacer política sólo definiendo leyes objetivas de lo social o comportamientos de las clases. En consecuencia, la alternativa política que promueve es el populismo, puesto que esta posición política tiene más en cuenta al sujeto que otras, representando para él la introducción del sujeto en lo político.

En síntesis, el vínculo entre política y psicoanálisis que el libro establece ayuda a pensar proyectos políticos emancipatorios que tengan en cuenta al sujeto y la posibilidad de llegar a las mayorías en una sociedad en la que el neoliberalismo produce subjetividades, lo que permite reflexionar en torno a las debilidades y fortalezas de distintas experiencias políticas como el chavismo en Venezuela, el Partido de los Trabajadores en Brasil, el kirchnerismo en Argentina y Podemos en España, y las razones por las cuales actualmente vencen en las elecciones proyectos políticos que perjudican a las mayorías.

La publicación de este libro evidencia, una vez más, la necesidad y la importancia de continuar reflexionando interdisciplinariamente en torno al capitalismo y sus efectos. Así, Horizontes neoliberales en la subjetividad es más que una crítica al neoliberalismo -sus mandatos, imperativos y exigencias-, es una respuesta a qué hacer con la tensión entre política -lo colectivo- y psicoanálisis -lo singular- en esta fase actual del capitalismo cuyo reflejo es un malestar psíquico que el psicoanálisis pretende tratar. De esta forma, contribuye a la comprensión de las formas de operar del dispositivo neoliberal, sus efectos en la subjetividad y la posibilidad de ponerle un límite al preguntarse cómo hacer del psicoanálisis un hecho político y qué elementos puede aportar el psicoanálisis para pensar lo que es inapropiable para los dispositivos neoliberales. Cabe entonces preguntarse: ¿Podrá interrumpirse esta “fábrica de subjetividades”? ¿Podrá el psicoanálisis ser el "freno de mano"? 